Tikka, P., \& Oinas-Kukkonen, H. (2019). Tailoring persuasive technology: A systematic review of literature of selfschema theory and transformative learning theory in persuasive technology context. Cyberpsychology: Journal of Psychosocial Research on Cyberspace, 13(3), article 6. https://doi.org/10.5817/CP2019-3-6

\title{
Tailoring Persuasive Technology: A Systematic Review of Literature of Self-schema Theory and Transformative Learning Theory in Persuasive Technology Context
}

\author{
Piiastiina Tikka \& Harri Oinas-Kukkonen ${ }^{1}$ \\ ${ }^{1}$ University of Oulu, Oulu, Finland
}

\begin{abstract}
Groundwork for understanding persuasion in human behaviour change through the human-computer environment has been laid by the socio-psychological paradigm and theories, and an acknowledged key element in behaviour change is the role of attitude in the intention-behaviour gap. The said gap is explored in the present paper by means of a systematic literature review of how theories of self-schema and transformative learning have been used thus far in researching behaviour change support systems. Tailoring content and persuasive strategies to some end-user traits is an acknowledged avenue in the persuasive technology field, but what identifiable traits beyond needs, interests, personality, or context can be identified and used in the pursuit of systems that are increasingly more relevant to their users? Various databases were searched for peer-reviewed articles, and the research contributions were analysed against the Persuasive Systems Design Model and Outcome/Change Design Matrix. The results show that neither theory has been used extensively for researching behaviour change support systems; yet, a closer look at the records offers feasible approaches for addressing the intention-behaviour gap. Both SST and TLT emerge as worth investigating as regards identifying and influencing attitude and self-perception level factors in persuasion.
\end{abstract}

Keywords: Persuasive technology; Behaviour change; self-schema theory; transformative learning theory; literature review

\section{Introduction}

Use of persuasive technology aiming at behaviour change has burgeoned in recent years particularly in the area of health and personal well-being. Through advances in information systems, their interfaces, and ever-increasing connectivity the possibilities for using information technology as a tool for influencing people have reached a point where systems designed for persuasion will work fluently and even with subtlety on the devices people carry with them almost all of the time. There is a substantial body of research into persuasive systems in the field of information systems (e.g., Abraham \& Michie, 2008; Chatterjee \& Price, 2009; Consolvo, McDonald, \& Landay, 2009; Fogg, 2009; Kuonanoja, Langrial, Lappalainen, Lappalainen, \& Oinas-Kukkonen, 2015; Lehto \& Oinas-Kukkonen, 2015), and much of the groundwork for how persuasion occurs in the human-computer environment stems from a socio-psychological paradigm, such as Bandura's (1977) social learning theory, Ajzen's (1991) theory of planned behaviour, or the elaboration likelihood model (Petty \& Cacioppo, 1986). A pivotal text in computerized persuasion research and development is Fogg's (2003) influential book, which in itself builds on the aforementioned sociopsychological paradigm. 
Tailoring persuasive systems and messages to users is an important component of systems design (Fogg, 2003; Kaptein \& Eckles, 2012; Oinas-Kukkonen \& Harjumaa, 2009), but without knowing enough about the context and the individual receiving the message it is difficult to tailor the messages and their delivery effectively. So far strategies for addressing specific types of system users have included targeting specific change goals or users' cognitive styles with positive results (Kaptein \& Eckles, 2012; Kaptein Markopoulos, de Ruyter, \& Aarts, 2015; Wheeler, Petty, \& Bizer, 2005). While psychological traits such as those identified by Petty and Cacioppo (1986) offer a relatively broad scope for tailored content in a persuasive system, for best effects it would appear beneficial to find further means of utilizing the full potential of modern information systems and offer persuasive content that does match the end-user's needs, interests, personality, context and other relevant factors. In other words, in striving to match systems to their users, the field could be enriched by exploring further means of understanding end-user traits when it comes to behaviour change. Another question, however, is the malleability of a person's concept of self. If one strategy for persuasive systems would be to match a message to the recipient, another avenue that can be seen is to try to influence the person's thinking as such: his or her attitude and outlook as regards the behaviour change goal.

In the present literature review we seek to address this by exploring another behavioural theory that has been discussed in existing literature in connection with persuasion and behaviour change: the self-schema theory (Cacioppo, Petty, \& Sidera, 1982; Markus, 1977). This theory deals with a person's perception and generalization regarding himself or herself with reference to a specific behavioural domain (Markus, 1977; Markus \& Wurf, 1987). Where Need for Cognition (Petty \& Cacioppo, 1986) distinguishes between message elaboration styles and thus can be used in determining optimal message delivery routes, the self-schema theory has the potential to advise the field on additional dimensions of how intention may or may not actualize as behaviour depending on a person's schematicism. By extension, we also explore transformative learning theory (Mezirow, 2009) as a potential behaviour change model that operates, for one, in the very area of self-schemas: the perception of self in relation to the surrounding world. An adult learning theory, transformative learning theory concerns a learning process for the purpose of the learner gaining ability to re-evaluate and change his or her own perspective as regards the surrounding world (Mezirow, 2009). The focus of change in transformative learning process is the learner's own approach to his or her surroundings, and in the learner's ability to engage in thinking about his or her own approach to situations. In Mezirow's (1997) approach to transformative learning, one of the areas of change involves a person's image of themselves, but also other habits of mind (as Mezirow has labelled such structures) such as feelings, beliefs, judgments and attitudes we harbour regarding the world are also present. Considering such approach alongside the concept of self-schemas that can be very domain specific (for example, how exercise prone a person may see him or herself), the question arises whether the two theories have been employed in the field of persuasive technology so far in terms of an opportunity for system tailoring. Transformative learning also requires for the learner to identify the need for change and then engage in the learning process (Mezirow 2009), which is a primary building block of Behaviour Change Support Systems (BCSS) (Oinas-Kukkonen, 2010a). BCSSs are, effectively, a defined category in the broader field of persuasive systems.

The present study, then, asks: how have the theories of self-schema and/or transformative learning been used in persuasive technology research to date? The study is conducted as follows: 1) we explore and discover how the theories of self-schema and transformative learning have been used in persuasive technology and behaviour change research so far in information systems, and 2) as a means of grounding the review findings in persuasive technology research we analyse the findings using design and evaluation tools for development of persuasive systems, the Outcome/Change (O/C) Matrix (Oinas-Kukkonen, 2010a, 2010b) and Persuasive Systems Development (PSD) model (Oinas-Kukkonen \& Harjumaa, 2009). By mapping findings from existing research to the O/C Matrix and the PSD model the present review highlights how persuasive technology research can tap into the added end-user characteristic understanding that self-schema theory can offer as an extension of those theories of social psychology that are already in use. By examining transformative learning (Mezirow 1981, 2009) we endeavour to identify a new opportunity for a practical approach to affecting attitudes and behaviour in the persuasive systems field. The results are expected particularly to support further research and system concepting in the field of persuasive technology and BCSSs. 


\section{Background}

In this section of the article we provide an overview of relevant background to the presented literature review in terms of how the focused theories of self-schema and transformative learning map to persuasion and behaviour change. The section also discusses the focused frameworks in the field of persuasive technology.

Behaviour Change Support Systems. For the design and development of these systems, Oinas-Kukkonen and Harjumaa (2009) provide a Persuasive Systems Design (PSD) model that draws together theories around persuasive technology and their psychological foundations, and proposes practical design and evaluation principles for the design and development of persuasive systems and, specifically, behaviour change support systems (BCSS) (Oinas-Kukkonen, 2010a, 2010b). Behaviour Change Support System (BCSS) is a concept in the field of persuasive information systems that can be defined as systems that are designed to form, alter and/or reinforce compliance, attitudes, and/or behaviours (Oinas-Kukkonen, 2013). BCSS is a research construct that answers to the need to accurately describe the actual software systems (their functionality, content, structure and intent) as regards behaviour change. At present, research into persuasive systems and behaviour change can be somewhat lacking in describing the systems used and thus it remains unclear exactly how and through which features and design change is achieved (Oinas-Kukkonen, 2013). In addition to having a strong theoretical basis and a measure of actual behaviour change, a BCSS involves the analysis of intent (what change a system is intended to produce) and analysis of the persuasive potential of a system (Oinas-Kukkonen, 2013).

Outcome/Change (O/C) matrix. The Outcome/Change (O/C) Matrix (Oinas-Kukkonen, 2010a, 2010b, 2013), in short, tracks change on two axes: change and outcome. Change occurs in compliance, behaviour and/or attitude, and the outcomes are the formation, alteration or reinforcement of any of the change types (Oinas-Kukkonen, 2010a, 2010b, 2013). For an iterative persuasion process, the presented research assesses the possibility and applicability of identifying concrete steps for when and how to build new persuasion content on top of existing behaviour change outcomes: that is, how to support the iterative nature of behaviour change. The development of persuasion success in terms of change in compliance, behaviour, and attitude can be approached in a systematic fashion through the use of the O/C Matrix.

In the O/C Matrix, the main stages and types of behaviour change have been categorized and labelled as C-, B-, and A-change, referring to compliance, behaviour and attitude respectively. C-change means the simple act of doing as requested (Oinas-Kukkonen, 2010a), for example, fill in the day's weight in a weight loss system when prompted. Compliance is not dependent on intrinsic motivation, but can still be used to induce target behaviour and thus support change in behaviour. B-change is a step further than simple compliance: it requires that an element of intrinsic motivation is in place, and the observed change is more enduring than a simple one-off compliance to a request (extrinsic) motivation (Oinas-Kukkonen, 2010a). Behaviour can happen and be sustained as a matter of self-efficacy or strong habit even when the internal attitude or habit structures do not make the behaviour automatic. For example, it is possible to simply make yourself rehearse an activity even when you dislike it. A-change for its part is a change that happens internally at the level of attitudes and preferences that direct behaviour. While sustaining B-change alone has been found to be difficult (Oinas-Kukkonen, 2010a), with the support of attitude level change the outlook on the target behaviour can be changed, thus making that behaviour more naturally occurring and fluent.

F-, A- and R-Outcomes are listed in the order of their perceived difficulty (Oinas-Kukkonen, 2010a). When no previous experience of a behaviour exists or an attitude is not yet present for a given subject, the process of establishing a behaviour for the first time or the emergence of an attitude is categorized as formation on the matrix. When an existing behaviour or attitude is changed, alteration takes place. Finally, when an existing behaviour is encouraged and attitude is strengthened, behaviour and attitude are reinforced.

According to Markus (1977), self-schemas take shape through experiences, from information that an individual has processed in the past. From there on the self-schema influences both the input and output of information regarding the self. Repeated accumulation of further experiences strengthens the self-schema and makes it increasingly resistant to inconsistent or contradictory information (Markus, 1977). Considering self-schema formation and reinforcement against the O/C Matrix, the similarities are, indeed, in the formation and reinforcement. To simplify, it would appear that a (positive and desired) behaviour that forms correctly to begin 
with can be reinforced and that there is hope that the behaviour and accompanying attitude develop to be resistant to disrupting influences. The challenge of behaviour and attitude change thus falls into the gap between formation and reinforcement: the alteration outcome, which is the outcome that most calls for understanding the schema structures that are in place prior to starting a change process. If there is some idea of the underlying attitude or self-schema prior to starting a behaviour change process, there should be more and better opportunities for selecting the appropriate persuasion route and strategies.

While self-schema structures reside in the area of F- and R-Outcomes, transformative learning could be a way of focusing on A-outcome. Transformative learning has been utilized particularly in adult learning: the learning that happens when a number of assumptions, schema structures and attitudes and behaviours have already formed (Mezirow, 2009). The elements of the process describe a path that intends to recognize existing patterns, which Mezirow describes as frames of references (Mezirow, 2009). Mezirow's definition of transformative learning probably best describes the target as "learning that transforms problematic frames of reference to make them more inclusive, discriminating, reflective, open, and emotionally able to change" (Mezirow 2009, p.22). In other words, the process can be regarded as targeting alteration in the O/C Matrix by aiming at causing a shift in selfschemas that do not facilitate desired behaviours.

The O/C matrix helps in analysing both what type of change and what outcome a system should aim for, and also what types of change and outcomes an existing BCSS supports. The matrix could also be used for tracking and evaluating a persuasion process as it takes place: a user's state in various stages of using a behaviour change support system can be analysed by using the matrix to see if desired change types have been reached at various points in the process.

One part of the incremental behaviour change is the change that takes place in terms of attitude (Oinas-Kukkonen, 2013). Attitude may not directly influence intention to use some system (Venkatesh \& Bala 2008; Venkatesh, Morris, Davis, \& Davis 2003), but its presence has been identified as a contributing factor in behaviour: the significance of attitude and personal abilities and facilitators regarding behaviour change is also presented in some of the core behaviour change theories, such as theory of planned behaviour (Ajzen, 1991), social learning theory (Bandura, 1997), and elaboration likelihood model (Petty \& Cacioppo, 1986). While these theories point to the necessity of a facilitating attitude as regards turning intention successfully into intended behaviour, it would be beneficial to explore further how attitudes and person-specific tendencies work in behaviour change. In particular, it would seem useful to see how an understanding of attitudes and person-specific tendencies has been taken into account in persuasive systems design.

Persuasive Systems Design model. The Persuasive Systems Design (PSD) model (Oinas-Kukkonen \& Harjumaa, 2009) is, essentially, a framework for the analysis and design of persuasive systems. It places the content and a set of persuasive software features in the context of a design and evaluation process of persuasive systems (OinasKukkonen \& Harjumaa, 2009). Together with the O/C Matrix the PSD model can be used as an analysis tool in the persuasive systems process between background theories and measuring behaviour change so that it would be possible to define and describe the software systems (and their intent) that are used in achieving behaviour change (Oinas-Kukkonen, 2013). The theoretical backbones of the PSD model include the elaboration likelihood model (Petty \& Cacioppo, 1986), theory of planned behaviour (Ajzen, 1985, 1991), social learning theory (Bandura, 1977) and goal-setting theory (Locke and Latham, 2002).

The present review will analyse which PSD features can be identified from the reviewed literature in so far as technology has been used as a part of the studies. In short, in the area of persuasive systems and technology the PSD model provides a catalogue of persuasive features and their use in the core elements of persuasive systems, namely primary task support, dialogue support, system credibility and social support (Lehto \& Oinas-Kukkonen, 2011).

\section{Intention-Behaviour Gap}

Self-schema theory. The theory of self-schema (Markus, 1977) defines a person's perception of what he or she is like in relation to his environment: it is "cognitive generalizations of the self, derived from part experience, that organize and guide the processing of self-related information contained in the person's social environment" ( $p$. 
64). Sheeran and Orbell (2000) found that a positive self-schema regarding exercising acted as a moderator in translating intention into actual behaviour. For example, theory of planned behaviour (Ajzen, 1985, 1991) attributes a great deal of our behaviour to our intentions, but as later health-related research has implied, intention at times explains as little as $50 \%$ of given behaviours (Sheeran \& Orbell, 2000). Research into selfschemas can, then, help us increase our understanding of the gap between intention and behaviour (Markus, 1977).

According to Markus (1977) once a self-schema has been established, it provides a selective function that determines what information is attended to, in what way that information is structured, and how important it is deemed to be. Self-schemas are reinforced when individuals encounter more of the same type of experiences that helped form the schema in the first place, and as the schemas gain strength they also become more resistive to schema-inconsistent information (Markus, 1977). However, the self-concept is also dynamic in that it is multifaceted and multidimensional and it is systematically present in all social information processing (Markus \& Wurf, 1987). The self-concept does not only describe behaviour but also mediates and regulates it (Markus \& Wurf, 1987).

Self-schema structure has been discussed in connection with message elaboration and attitude change (Wheeler et al., 2005). Self-schema research (i.e. Markus, 1977; Sheeran \& Orbell, 2000) has indicated a direct link in how a person's self-schema explains behaviour and behaviour change. Wheeler et al. (2005) propose that a message that matches a person's self-schema as regards Need for Cognition results in higher elaboration. On the whole, the elaboration of (persuasive) messages means the kind of critical thinking where a person integrates new information with existing information and thus generates new information and new associations (Cialdini, Petty, \& Cacioppo, 1981).

Theory of transformative learning. The field of computerized behaviour change already builds heavily on social psychology and applies it to persuasion techniques and their application in persuasive systems. In order to complement the socio-psychological approach to the change process, it should be a reasonable step to borrow further theories regarding behaviour change from another applied field and observe behaviour change as a learning process. It is for this reason that the present paper looks to learning theories, and in particular transformative learning theory (Mezirow, 1995), as a means of assisting behaviour change with BCSSs. In education research, and particularly in the context of adult learning, Mezirow's Theory of Transformative Learning (Mezirow, 1981) builds on constructs of re-evaluating one's position in the face of new information or changed situations. Transformative learning is a structured programme of changing one's understanding of the surrounding world in order to achieve deep learning, which could also be interpreted as change. An adult learner takes on the goal of becoming an autonomous responsible thinker, that is, to achieve a change in how he or she approaches the world and thus behaves in it. In a similar fashion, as seen in the definition of what a Behaviour Change Support System is, a system user is someone who takes on a change goal, aiming at changing their thinking and their behaviour.

In transformative learning (Cranton 1994,1996; Mezirow 1991, 1995,1996) a key element subsists in self-reflection of one's experience, which will eventually lead to a change in how a person views himself or herself in relation to the surrounding world. Self-reflection both on action and also in action (Ploderer, Reitberger, Oinas-Kukkonen, \& van Gemert-Pijnen, 2014) encourages behaviour change through increased self-knowledge, and has reached notable prominence in the area of behaviour change technology for example in health domain self-tracking and as the Quantified Self movement (Ploderer et al., 2014). Mezirow's emphasis is on critical self-reflection (Mezirow, 1997), highlighting the need for the ability to critically assess any new information that is not in line with what a person already knows. In order to overcome potential cognitive dissonance (Festinger 1962), such ability to review and elaborate on new and potentially conflicting information would seem a necessary skill. The stages of transformative learning, particularly stages 2 and 3 (see later in this section) pay attention to taking the necessary steps to incorporate such reflection in the change process. The required skillset involves more than (critical) selfreflection which has been highlighted in the present paper as a common thread as regards acknowledged behaviour change tools. These skills build towards increased awareness of one's own thinking and behaviour, understanding others' positions and perspectives and communication with them, and learning how to plan (and carry out these plans) new courses of actions, to mention a few. On the whole, such skill sets would support acknowledged behaviour change tools such as goal setting (Locke \& Latham, 2002), feedback for reflection as in 
self-monitoring in persuasive systems (Oinas-Kukkonen \& Harjumaa, 2009) and social aspects of learning behaviours (Bandura, 1977).

Transformative learning shares common ground with the elaboration likelihood model (Petty \& Cacioppo, 1986) in the way both emphasize the role of self-reflection: in the elaboration likelihood model the direct route of persuasion is concerned with high elaboration of the message (reflection), and in transformative learning selfreflection leads to a changed perspective. Basic concepts in the elaboration likelihood model (critical thinking and other methods of self-persuasion, creating new information yourself) are highly reminiscent of some elements of transformative learning theory, where the core concept is to change a person's perspective as regards the learning objective through critical thinking, critical self-assessment, and using methods such as role play (Mezirow, 1997; Mezirow, 2009). As a practical approach to elaboration Cialdini et al. (1981) point to, for example, role play with regard to self-persuasion, and highlight how information we generate for ourselves is more persuasive than information provided by others.

Transformative learning is also a stage-based learning model and as such there are similarities to other established stage models in the area of behaviour change, such as the transtheoretical model (Prochaska \& DiClemente, 1983), which has been widely used in the area of health-related behaviour change. However, it is the explicit goal of changing a learner's perspective to the world around him that makes transformative learning theory of interest in the context of self-schema and the possible incremental steps towards affecting self-schemas and producing incremental behaviour change. Mezirow (1997) talks of "habits of mind" and "point of view", describing these in many ways similarly to some descriptions of attitudes or even self-schemas: as habitual ways of thinking, feeling or acting that are based on a set of codes that are strongly linked to how a person relates himself to his environment. A change in perspective regarding experiences means a change in these codes.

Transformative learning as a process is defined through stages that take the learner through the learning topics by means of critical self-reflection with the aim of changing the learner's perspective (Mezirow, 2009). Mezirow describes the transformative process through ten stages that start from the initial recognition that there is an issue that needs to be addressed (Mezirow, 2009). The ten stages are (as defined in Mezirow, 2009, p.19): (1) A disorienting dilemma, (2) Self-examination, (3) A critical assessment of assumptions, (4) Recognition of a connection between one's discontent and the process of transformation, (5) Exploration of options for new roles, relationships, and action, (6) Planning a course of action, (7) Acquiring knowledge and skills for implementing one's plan, (8) Provisional trying out of new roles, (9) Building competence and self-confidence in new roles and relationships, and (10) A reintegration into one's life on the basis of conditions dictated by one's new perspective. These stages require the learner to proceed from acknowledging a problem to reflecting upon its potential reasons and effects to rehearsing target behaviours and planning ahead (setting new goals), and finally obtaining means to maintain the new perspectives and behaviours - somewhat as described more simply in the O/C matrix as moving from compliance to behaviour change and on to obtaining a change in attitude. Such a process will necessarily require more than self-reflection, but a degree of considering one's own actions and thoughts is present throughout the set path.

Self-schema, as a construct built of our experiences and observations in our social environment (Markus, 1977) is at least in part a structure that represents the perspectives which transformative learning aims to change. Naturally there are also other descriptions of the same concept of a self-image and how we place ourselves within our environment, such as 'response shift'1 in quality of life research (Barclay-Goddard, King, Dubouloz, \& Schwartz, 2012). In terms of BCSSs and understanding the process of behaviour change alongside a shift in attitude, a comparison of approaches and a comparison of identified steps in the process in each of the theories should provide a good starting point for deepening our understanding of the behaviour and attitude change process as described in the O/C Matrix. The results of such understanding can be used in the design of incremental persuasion, possibly by developing concrete steps that support the utilization of the persuasion context elements in the PSD model (Oinas-Kukkonen \& Harjumaa, 2009).

\section{Method}

A systematic review of literature aims at uncovering as much of the relevant literature as possible and does so through a pre-defined search strategy and methods (Kitchenham, 2004; Webster \& Watson, 2002). By means of 
systematic literature review, it is possible to summarize existing evidence regarding the research topic, to identify any gaps in the existing literature regarding the topic, or to provide background in order to position and orient new research activities (Kitchenham, 2004). The present paper involves the latter two intentions. The key elements of the method involve pre-defined strategies for the research so that the review can be carried out in a rigorous manner, and that the strategies allow for full and fair discovery of relevant records (Kitchenham, 2004). The stages of the research involve specifying search criteria in accordance with the research question, identifying suitable corpuses, carrying out the searches, assessing applicable records (described in further detail later on), and data synthesis before reporting activities (Kitchenham, 2004; Webster \& Watson, 2002).

\section{Identification of Studies}

In order to conduct a systematic review of the literature in the field of persuasive systems, we performed an electronic literature search in Scopus, EBSCO (Academic Search Premier), and ProQuest databases. The selected corpuses represent a significant volume of information systems and related research. Information systems is a heavily multidisciplinary field (Webster \& Watson, 2002) and as such literature relevant to the very multidisciplinary research question posed by the present paper may be spread widely between applied fields of research. The target was to identify publications that discussed the theories of self-schema and/or theory of transformative learning in the contexts of behaviour change and/or persuasive technology. The search did not limit publication years. Figure 1 illustrates the search model for relevant papers in the area of interest.

The searches were conducted using combinations of following the search terms: 1) "self-schema", "transformative learning", 2) persuasi*, behavio(u)r change, and 3) information system(s). After the exclusion process, the bibliographies of the remaining articles were screened for other relevant articles that might not have been caught in the process up until that point. The bibliography screening included any meta-analyses and systematic reviews that had been discovered. Figure 2 illustrates the process of elimination of papers.

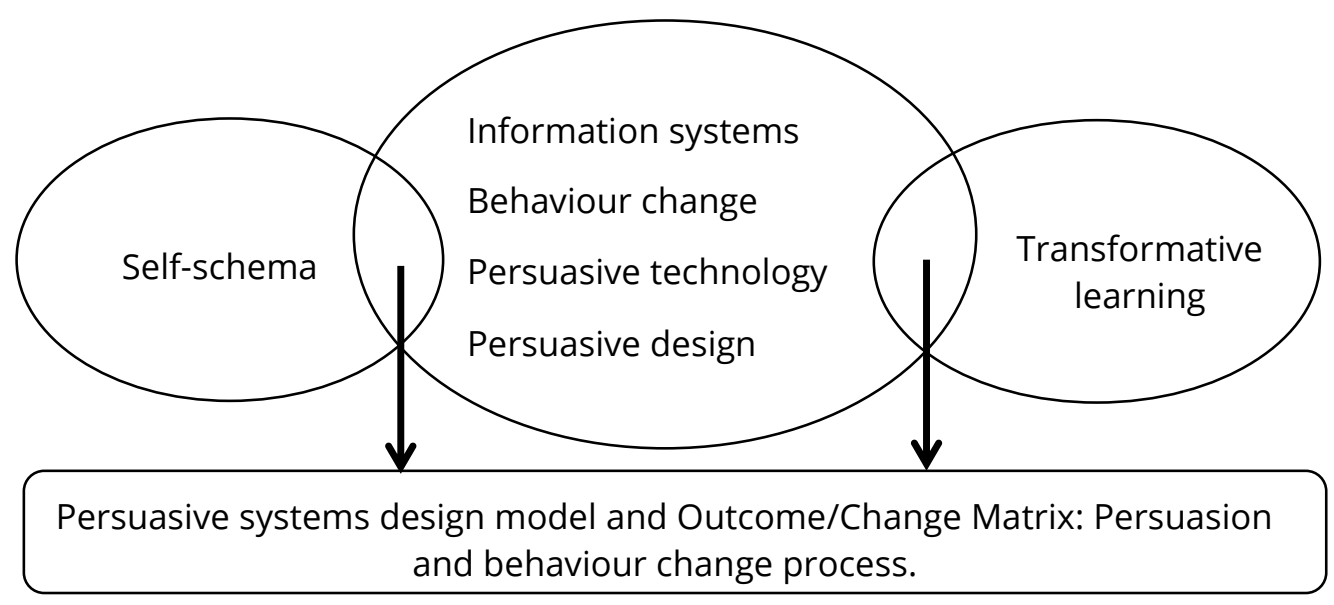

Figure 1. Overview of the literature search.

\section{Inclusion and Exclusion Criteria}

For the review of the use of theories of self-schema and transformative learning in computerised persuasion, articles were included at the initial stage if they discussed behaviour change, persuasive technology, persuasive design or persuasion as such with regards to either the theory of self-schema or transformative learning. In addition, included articles had to come from peer-reviewed journals or conference proceedings. These concepts (Webster \& Watson, 2002) were used systematically with each database search with the help of a specialist information scientist to ensure that search terms remained constant across search systems. 
After the searches on each of the databases were completed, the exclusion was done in stages:

Stage 1: Scanning of found documents on the basis of their subject matter and topic. Papers that clearly dealt with education and learning in general, mental health in the medical field, or behaviour change articles that clearly did not consider either transformative learning or self-schema were excluded at this point in order to focus the review specifically on behaviour change and persuasion rather than treatment of illnesses or mental health conditions or learning and education in general. In practice, at this stage 446 records out of the total 496 were excluded by scanning through their titles and abstracts and thus identifying their topics and themes. 50 articles were included for further evaluation. The excluded articles were all clearly off topic (dealing with tourism, gaming, personality studies, etc.), focusing on education and learning, or mental health/medical conditions (such as depression or ADHD).

Stage 2: Exclusion based on abstracts. Again, the above criteria were applied to the papers. At this point 30 records were extracted from the set, and the remaining 20 papers were used in carrying out the backward and forward checks. Stage 1 and 2 procedures were performed on these extra items, excluding 11 records. Overall, after stage 2, 29 items were carried through to the final stage.

Stage 3: Exclusion based on full paper. At this point, the remaining articles were read through carefully to determine their topic, and how well they matched the targets set in the present review: behaviour change, persuasive technology, information system, self-schema and transformative learning (or combinations thereof, see Figure 1). A total of 20 papers were finally included in the literature analysis. All of these papers were journal publications.

The references sections in the papers that were included were scanned in order to identify possible further papers that could be checked against the same criteria (backwards check). A forward check was also conducted using Web of Science database in order to check through further papers that refer back to the selected papers. Such backward and forward checks are recommended by Webster and Watson (2002) for the purpose of identifying relevant articles that are closely connected to the topic of the search even if they have not been caught in the keyword search per se.

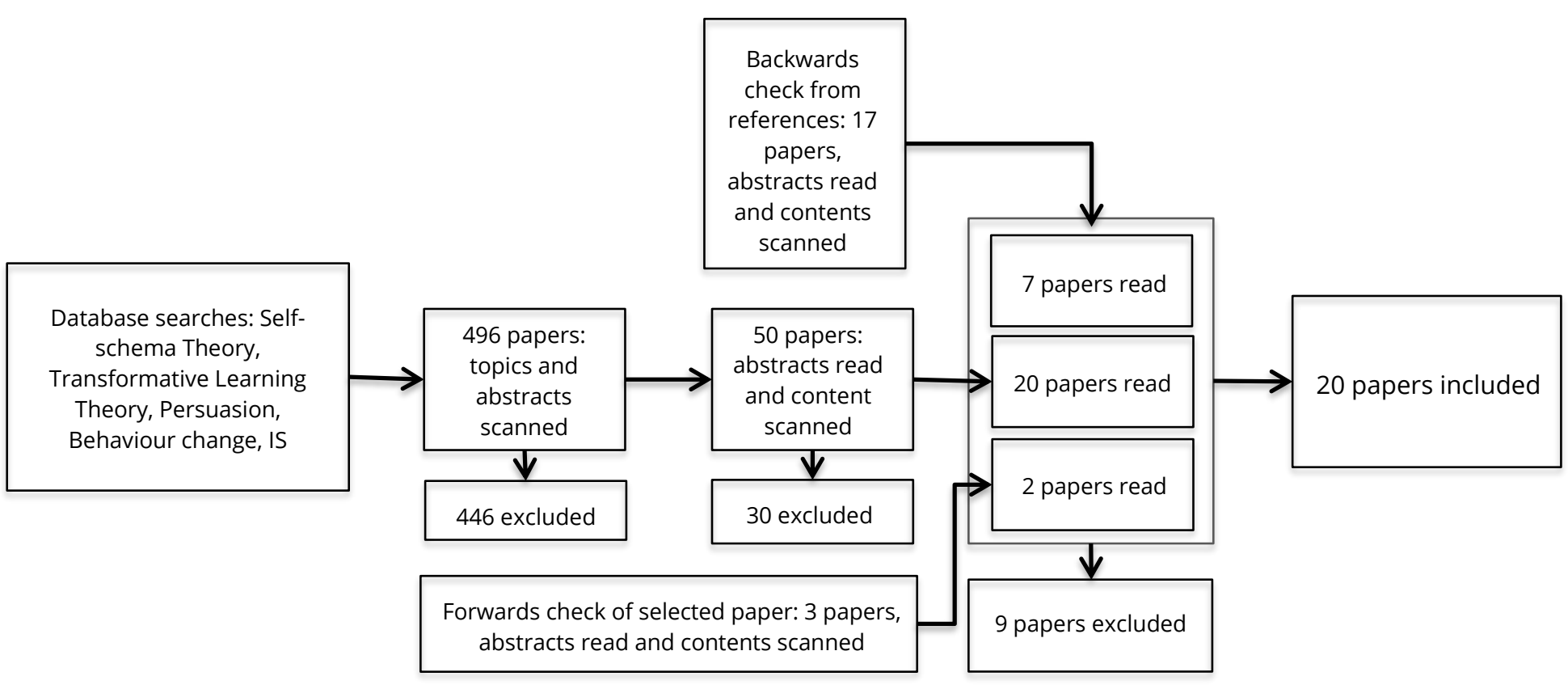

Figure 2. Process of elimination of papers.

The target of the present literature review was, as stated, to identify peer-reviewed publications that discussed persuasion, persuasive design, persuasive technology and behaviour change in connection with either selfschema theory or the theory of transformative learning - and primarily to do so in connection with computerized persuasion, in effect a BCSS. From the start it was clear that the two theories of interest have not been used as key terms in behaviour change support systems much, and the present review thus also includes behaviour 
change and persuasion related articles that consider the two theories in connection with other considerations of persuasion. The key definition here is that persuasion is an attempt to change another person's attitudes, behaviour or both (Fogg, 2003). Generally speaking, papers that did not discuss behaviour change specifically, as defined above, were excluded, though some of those papers (Barclay-Goddard et al., 2012; Cialdini et al., 1981; Markus, 1977; Markus \& Wurf, 1987; Petty \& Cacioppo, 1986) are present in this review as part of describing and illustrating the background theories.

\section{Data Abstraction}

As a result of the exclusion process illustrated in Figure 2, a total of 20 papers were included in the present review. The selected articles were examined and evaluated carefully for their contribution to the topics of interest in the present review: the roles and application of self-schema theory and theory of transformative learning in computerized persuasion. The articles were coded using a form that was constructed on the basis of the O/C Matrix. The coding aimed at identifying the types of change in behaviour or response to persuasion and the type of behaviour outcome that followed.

\section{Results}

To sum up, the final selection of articles included 5 papers which contained either self-schema or transformative learning and a persuasion element or information system as key components of the study. The majority of the selected studies satisfied the search terms by presenting behaviour change or persuasion (mostly behaviour change) together with the theoretical key components of self-schema or transformative learning. On the whole, the result is not surprising: after all, the search targeted very specific theories outside the more widely used ones of theory of planned behaviour (Ajzen, 1991), self-efficacy theory (Bandura, 1997) or elaboration likelihood model (Petty \& Cacioppo, 1986). One objective of the present review was to cast a roaming eye over further theories of behaviour that might support and add detail to the already acknowledged approaches. Another objective was to learn about transformative learning as a potentially useful addition to the behaviour change and persuasive technology design toolbox - given how the theoretical considerations discussed earlier on in the present review would appear to support introducing transformative learning theory to the field. As regards these two objectives, the selected studies do present viewpoints and practical considerations that have not to date made an appearance in the field of information systems or, more broadly, in the field of persuasive technology.

Of the twenty selected studies, only five satisfied the search terms to the fullest degree by having the three concepts of behaviour change/persuasion and self-schema/transformative learning and an information systems component present: Dijkstra (2008); Pilling and Brannon (2007); Wilkerson, Danilenko, Smolenski, Myer, and Simon Rosser (2011); York, Brannon, and Miller (2012a), York, Brannon, and Miller (2012b). Characteristics of the twenty reviewed articles are presented in Table 1, where the five studies that satisfied the search criteria are presented in bolded typeface.

Dijkstra's (2008) viewpoint paper discusses three specific features of computerized persuasion that would, in his experience and based on previous research, improve the persuasive quality of such systems. The paper, then, does not present an actual persuasive artefact or any new data towards verifying the presented features, but the theoretical connections and arguments speak for the benefits of matching persuasive features to the individual using the system.

Pilling and Brandon (2007), York et al. (2012a, 2012b) all approach behaviour and persuasion in terms of schema matching. In these three papers the technology component is a website simulation, where the message delivery depends on the personality types of the users. Finally, Wilkerson et al. (2011) is the only one where principles of transformative learning have been used as a part of the persuasive system. The paper highlights the role of critical self-reflection of assumptions in the intervention design and proposes that self-reflection is a facilitating factor in why a person would change their appraisal of their own behaviour over the intervention period. The technology use in the Wilkerson et al. (2011) study is not described in detail, referring only generally to Fogg (2003) as the basis for the design. 
Table 1. Characteristics of the Reviewed Articles.

\begin{tabular}{lc}
\hline $\begin{array}{l}\text { Author(s) } \\
\text { (year) }\end{array}$ & Topic \\
\hline $\begin{array}{l}\text { Allom and } \\
\text { Mullan (2012) }\end{array}$ & $\begin{array}{l}\text { Observing the role } \\
\text { (influence) of self- } \\
\text { schema on fruit and } \\
\text { vegetable consumption, } \\
\text { and examining the } \\
\text { validity of theory of } \\
\text { planned behaviour in } \\
\text { predicting fruit and } \\
\text { vegetable consumption. }\end{array}$
\end{tabular}

Use of self-schema theory

or theory of transformative

learning

Participants filled in

questionnaires regarding their fruit and vegetable

consumption cognitions, took two tests regarding selfregulation and eating habits and were monitored two weeks later with another questionnaire on their

behaviour. Based on the tests and surveys intention-

behaviour was compared between healthy-eater schematics and nonschematics.

Back, Egloff, Using explicit and
and Schmukle implicit self-concept of (2009) personality to predict actual behaviour.

The paper uses explicit (big

five) and implicit (IAT) selfconcept. Although the

concept of self-schema is not mentioned as such, the description of implicit selfconcept is very similar to the concept of self-schema and the paper has been included in the review.

Banting,
Dimmock, and
Lay (2009)

Using the implicit and

explicit components of an exerciser self-schema in predicting exercise behaviour.

Exercisers filled in questionnaires to determine their explicit exerciser selfschema type and their exercise intentions. They also completed an implicit association test (IAT) to determine their implicit exerciser schema. Their actual exercise behaviour was measured.

\begin{tabular}{|c|c|c|c|c|}
\hline $\begin{array}{l}\text { Beacham, } \\
\text { Stetson et al. } \\
(2011)\end{array}$ & $\begin{array}{l}\text { Role of exercise } \\
\text { schemata in the } \\
\text { perceived success/failure } \\
\text { of self-determined } \\
\text { exercise goals. }\end{array}$ & $\begin{array}{l}\text { Theories of self-schema and } \\
\text { also attribution theory used. }\end{array}$ & $\begin{array}{l}\text { No persuasive } \\
\text { technology. }\end{array}$ & $\begin{array}{l}\text { Exerciser schematics tend to exercise } \\
\text { more (frequency/intensity) and they } \\
\text { also have higher levels of self- } \\
\text { efficacy and more positive outcome } \\
\text { expectations for exercise. }\end{array}$ \\
\hline $\begin{array}{l}\text { Brannon and } \\
\text { McCabe } \\
(2002)\end{array}$ & $\begin{array}{l}\text { Experiments into } \\
\text { demonstrating the } \\
\text { effectiveness of } \\
\text { matching public health } \\
\text { messages to self- } \\
\text { schematic preferences. }\end{array}$ & $\begin{array}{c}\text { Schema correspondence } \\
\text { theory was used. }\end{array}$ & $\begin{array}{l}\text { No persuasive } \\
\text { technology. }\end{array}$ & $\begin{array}{l}\text { Increased processing of the schema- } \\
\text { matched messages can impact the } \\
\text { effectiveness of the message. }\end{array}$ \\
\hline $\begin{array}{l}\text { Cacioppo, } \\
\text { Petty, and } \\
\text { Sidera (1982) }\end{array}$ & $\begin{array}{l}\text { Matching self-schema } \\
\text { type to a message } \\
\text { perspective. }\end{array}$ & $\begin{array}{l}\text { Effect of self-schema on how } \\
\text { message content is perceived. }\end{array}$ & $\begin{array}{l}\text { No persuasive } \\
\text { technology. }\end{array}$ & $\begin{array}{l}\text { In persuasion, cognitive responses } \\
\text { tend to be subjectively rational } \\
\text { rather than objectively rational. }\end{array}$ \\
\hline $\begin{array}{l}\text { Dijkstra } \\
(2008)\end{array}$ & $\begin{array}{l}\text { Computer-tailored } \\
\text { persuasion; effects of } \\
\text { three tailoring } \\
\text { ingredients (adaptation, } \\
\text { personalization and } \\
\text { feedback). } \\
\end{array}$ & $\begin{array}{c}\text { Persuasive effects of } \\
\text { computer-tailored persuasion } \\
\text { content are described and } \\
\text { explained using different } \\
\text { psychological processes, } \\
\text { including self-schemas. } \\
\end{array}$ & $\begin{array}{l}\text { Computerized } \\
\text { persuasion at an } \\
\text { abstract level (no } \\
\text { actual system } \\
\text { described). }\end{array}$ & $\begin{array}{c}\text { Adaptation, personalization and } \\
\text { feedback are different and appear to } \\
\text { affect different psychological } \\
\text { processes. }\end{array}$ \\
\hline $\begin{array}{l}\text { Ennigkeit and } \\
\text { Hänsel (2014) }\end{array}$ & $\begin{array}{l}\text { Testing how exerciser } \\
\text { self-schema affects the } \\
\text { processing of self- } \\
\text { relevant information in } \\
\text { the context of sport and } \\
\text { exercise. }\end{array}$ & $\begin{array}{l}\text { Self-schema was used as the } \\
\text { basis of the hypothesis that } \\
\text { schematics would prefer } \\
\text { consistent feedback over } \\
\text { positive feedback. }\end{array}$ & $\begin{array}{l}\text { No persuasive } \\
\text { technology. }\end{array}$ & $\begin{array}{l}\text { Hypothesis was not confirmed, and } \\
\text { instead the results indicate that } \\
\text { exercise schematics might devalue } \\
\text { negative feedback more than non- } \\
\text { schematics. }\end{array}$ \\
\hline
\end{tabular}

Implicit and explicit exerciser self-
Use of technology Surveys and questionnaires were computerized, but the experiment did not involve persuasive technology.
Summary of results/conclusions

Self-schema did not affect the relationship between intention and behaviour, but in examining the data based on the various categories of self-schema, the researchers found that for healthy-eating schematics self-regulation is an important moderator of intention and behaviour. For the non-schematics habit strength influences the intention-behaviour relationship.

\author{
No persuasive \\ technology.
}

The observations confirm that selfreported personality (Big Five questionnaire) does have predictive importance. Implicit personality measures also predict behaviour for neuroticism and extraversion, but not for openness or conscientiousness. The "implicit measures of personality remained stable when controlling for explicit measures". schemas are connected. However, they are individual constructs. Thus, it is important to try and understand both schemas (implicit and explicit) when attempting to predict exerciser behaviour. 


\begin{tabular}{lr}
\hline $\begin{array}{l}\text { Author(s) } \\
\text { (year) }\end{array}$ & \multicolumn{1}{c}{ Topic } \\
\hline $\begin{array}{l}\text { Kendzierski, } \\
\text { and Sheffield } \\
(2000)\end{array}$ & $\begin{array}{r}\text { Role of self-schemas in } \\
\text { exercise lapse. }\end{array}$ \\
\hline
\end{tabular}

\section{Use of self-schema theory \\ or theory of transformative learning}

Exerciser schematics and aschematics explained their exercise lapses. They were also asked about a lapse in another (non-exercise) activity.
Use of technology

No persuasive technology.

The attributions made by aschematics as to their exercise lapse were more stable than with schematics as regards exercise. With the non-exercise activity lapse the groups did not differ. Thus, the attributional differences in due to exercise lapses were because of differences in attributional style.

Kendzierski, Sheffield, and Morganstein (2002)

\section{Types of attributions when considering one's own or others' exercise lapse, and the role of self-schema in that context.}

\section{Differences between \\ schematics and non-} schematics in the way they make attributions regarding exercise lapses not only with their own behaviour but also when asked about others' lapses.

\section{No persuasive technology.}

Exercise schematics' attributions were less stable when considering their own lapses, but equally stable as with those without the exerciser self-schema when considering "others". The causes for lapses were similar between the two groups, but the stability depended on the perspective difference between the groups: to the schematics the reasons for lapses were something that could be overcome.

\begin{tabular}{|c|c|c|c|c|}
\hline $\begin{array}{l}\text { Kendzierski } \\
\text { (1988) }\end{array}$ & $\begin{array}{l}\text { Examining differences } \\
\text { between exerciser } \\
\text { schematics, non- } \\
\text { schematics and } \\
\text { aschematics in terms of } \\
\text { their self-reported } \\
\text { exercise behaviour and } \\
\text { their thoughts and } \\
\text { feelings regarding } \\
\text { exercise. }\end{array}$ & $\begin{array}{l}\text { Self-schemas are the key } \\
\text { variable in the study. }\end{array}$ & $\begin{array}{l}\text { No persuasive } \\
\text { technology. }\end{array}$ & $\begin{array}{l}\text { Exerciser schematics exercised more } \\
\text { frequently and showed other } \\
\text { positive intentions and behaviours } \\
\text { towards exercising. }\end{array}$ \\
\hline $\begin{array}{l}\text { Pease, } \\
\text { Brannon, and } \\
\text { Pilling (2006) }\end{array}$ & $\begin{array}{l}\text { Schema correspondence } \\
\text { theory applied to } \\
\text { selective exposure to } \\
\text { health information. }\end{array}$ & $\begin{array}{l}\text { The study was interested in } \\
\text { when people expose } \\
\text { themselves to health } \\
\text { information that has been } \\
\text { tailored to their particular } \\
\text { self-schemas. }\end{array}$ & $\begin{array}{l}\text { No persuasive } \\
\text { technology. }\end{array}$ & $\begin{array}{l}\text { On the whole, recipient self-schema } \\
\text { matched. Information was preferred } \\
\text { over behaviour schema matching. }\end{array}$ \\
\hline
\end{tabular}
other two).

\begin{tabular}{lcccc}
\hline $\begin{array}{l}\text { Pilling and } \\
\text { Brannon }\end{array}$ & Assesses students' & Self-schema matching & Web-site & Using a more personalized (schema- \\
$\mathbf{( 2 0 0 7 )}$ & attitudes regarding & (schema corresponding & simulation of & based) approach resulted in more \\
& messages promoting & theory) as one persuasion & three intervention & favourable attitudes towards the \\
& responsible drinking in & strategy (social norms and \\
order to identify possible & aphaviour match being the & aproaches. & messages promoting responsible \\
& strategies of designing & other two). & & drinking.
\end{tabular}

strategies of designing

binge drinking

interventions.

\begin{tabular}{|c|c|c|c|c|}
\hline $\begin{array}{l}\text { Samenow, } \\
\text { Worley, } \\
\text { Neufeld, } \\
\text { Fishel, and } \\
\text { Swiggart } \\
\text { (2013) }\end{array}$ & $\begin{array}{l}\text { Transformative learning- } \\
\text { based course for } \\
\text { workplace behaviour } \\
\text { change (for disruptive } \\
\text { physicians). A case study. }\end{array}$ & $\begin{array}{l}\text { Transformative learning } \\
\text { process forms the basis for a } \\
\text { 10-step course in adjusting } \\
\text { disruptive behaviour in a } \\
\text { workplace. }\end{array}$ & $\begin{array}{l}\text { No persuasive } \\
\text { technology. }\end{array}$ & $\begin{array}{l}\text { The critical reflection and other steps } \\
\text { that aim at altering a person's } \\
\text { perspective on the surrounding } \\
\text { world and thus adjust his/her } \\
\text { behaviour in it appears to lead to } \\
\text { improvements in behaviour, as } \\
\text { reported by the case study subject's } \\
\text { colleagues. }\end{array}$ \\
\hline $\begin{array}{l}\text { Shadel and } \\
\text { Cervone } \\
(2011)\end{array}$ & $\begin{array}{l}\text { Role of self in smoking } \\
\text { initiation and smoking } \\
\text { cessation. }\end{array}$ & $\begin{array}{c}\text { Discussion of the self-concept } \\
\text { as a dynamic cognitive } \\
\text { structure regulating } \\
\text { behaviour. }\end{array}$ & $\begin{array}{l}\text { No persuasive } \\
\text { technology. }\end{array}$ & $\begin{array}{l}\text { Based on a dynamic view of the self- } \\
\text { concept, it can be said that the self- } \\
\text { concept has an important role in } \\
\text { regulating for example adolescents' } \\
\text { response to cigarette advertising, } \\
\text { etc. }\end{array}$ \\
\hline
\end{tabular}




\begin{tabular}{lc}
\hline $\begin{array}{l}\text { Author(s) } \\
\text { (year) }\end{array}$ & Topic \\
\hline $\begin{array}{l}\text { Stein and } \\
\text { Markus (1996) }\end{array}$ & $\begin{array}{c}\text { Role of self in } \\
\text { behavioural change. }\end{array}$
\end{tabular}

Use of self-schema theory

or theory of transformative learning

Markus (1996) behavioural change.
The paper examines how self-

schemas, possible selves and total self-concept function at each of the identified three

phases of behavioural change.
Use of technology

No persuasive
technology.

\section{Resistance to change is automatic,} natural and also expected result of the information processing and affect regulation that takes place when self-concept is compromised. A three-phase process of behavioural change is identified.

\begin{tabular}{lccc}
\hline Wheeler, & The paper explores & The relationship between & No persuasive \\
Petty, and & when schema & message quality and self- & technology. \\
Bizer (2005) & correspondence occurs. & schema matching is explored. &
\end{tabular}

\begin{tabular}{lccc}
\hline Wilkerson, & Sexual risk reduction/HIV & Transformative learning & Internet (online \\
Danilenko, & prevention intervention: & theory (critical self-reflection & trial) \\
Smolenski, & the cognitive and & assumptions, CSRA, in & \\
Myer, and & behavioural changes in & particular) considered as one & \\
Rosser (2011) & the intervention and & reason for how target users & \\
& $\begin{array}{c}\text { control participants in an } \\
\text { online HIV prevention } \\
\text { intervention. }\end{array}$ & $\begin{array}{c}\text { perceive their own behaviour } \\
\text { as part of the behaviour } \\
\text { change process. }\end{array}$ &
\end{tabular}
With schema-matched messages, persuasion increases or decreases depending on the argument quality of the message.

Intervention recipients appeared more likely to change beliefs and behaviours. Also, participants who reported no change in their beliefs and behaviours also indicated the least (or no) CSRA. Where both control participants and intervention participants reported CSRA, the intervention participants appeared to have more information to inform their thoughts processes.

\begin{tabular}{lccc}
\hline $\begin{array}{l}\text { York, } \\
\text { Brannon, and }\end{array}$ & Making responsible & Personality matching based & Web-based, but \\
Miller (2012a) & on self-schema theory. & no details \\
& $\begin{array}{c}\text { messages more } \\
\text { pealing by tailoring to } \\
\text { personality and }\end{array}$ & & provided. \\
& matching to context.
\end{tabular}

Schema matching, where the
message insisted that irresponsible drinking was inconsistent with a person's personal beliefs and values, had a greater positive impact in "staying in" context whereas it had no impact in "going out" situations, potentially owing to social factors. On the whole, interventions using schema matching can benefit from using tailored messages as well as from presenting the messages in a context with some congruency. For example, embed the anti-binge drinking message onto a website advertising bar specials, etc.

\begin{tabular}{|c|c|c|c|c|}
\hline $\begin{array}{l}\text { York, } \\
\text { Brannon, and } \\
\text { Miller (2012b) }\end{array}$ & $\begin{array}{c}\text { Comparing effectiveness } \\
\text { of responsible drinking } \\
\text { messages that have } \\
\text { been tailored to three } \\
\text { possible personality } \\
\text { conceptualization. }\end{array}$ & $\begin{array}{l}\text { Three personality matches } \\
\text { tested: personality type (big } \\
\text { five inventory, BFI), ideal self- } \\
\text { schema, and actual self- } \\
\text { schema. }\end{array}$ & $\begin{array}{c}\text { Web-based, but } \\
\text { no details } \\
\text { provided. }\end{array}$ & $\begin{array}{l}\text { On the whole, message } \\
\text { persuasiveness had an effect on } \\
\text { both the attitude towards the } \\
\text { message and also on the beliefs } \\
\text { regarding the message content } \\
\text { (binge drinking). The impact was } \\
\text { greater when the message was } \\
\text { either self-schema matched or BFI } \\
\text { tailored, but BFI tailoring (while more } \\
\text { complex) was no more effective than } \\
\text { self-schema matching. Ideal self- } \\
\text { schema matching was least effective } \\
\text { throughout. }\end{array}$ \\
\hline
\end{tabular}

Of the remaining fifteen studies in the review selection, one article (Samenow, Worley, Neufeld, Fishel, \& Swiggart, 2013) considered the concepts of transformative learning and behaviour change, and also presented a behaviour change programme. The paper was a composite case study describing the steps of the behaviour change programme intended to help disruptive physicians change their workplace behaviour in a more appropriate direction. The programme was based on the ten-step transformative learning model (Mezirow, 2009). The study and the programme described in it do not involve a computerised element, but as it was the one paper discussing transformative learning and behaviour change (and not pedagogics) the paper was included in the review. 
Finally, the remaining fourteen papers in the selection discuss self-schema and behaviour, predominantly from the viewpoint of predicting behaviour on the basis of schematicism. This final set of papers does not include any that consider either behaviour prediction or change as regards transformative learning and with reference to the exclusion criteria, it would seem that theory of transformative learning has, so far, remained more in the education domain. In a small number of these fourteen papers $(N=4)$ the focus was on the effect and reception of schemamatched messages to message processing (Brannon \& McCabe, 2002; Cacioppo et al., 1982; Pease, Brannon, \& Pilling, 2006; Wheeler et al., 2005), but were not expressing a specific behaviour change or persuasion objective.

Schema matching and persuasion offer an interesting avenue for the study of behaviour change, and particularly persuasive technology, as proposed by Dijkstra (2008). By matching the persuasion to the recipient as closely as possible it should be feasible to achieve more relevant and effective change, and in achieving such matching in persuasive systems that aim at catering for a wider audience it is computerized systems that are in the best position to offer functional solutions (Dijkstra, 2008; Oinas-Kukkonen, 2013; Oinas-Kukkonen \& Harjumaa, 2009).

\section{Persuasive System Features in the Studies}

The persuasive systems design features table (Table 2) lists, in short, the identified PSD features used in those studies and papers that included a persuasive technology component. A phenomenon already identified with persuasive systems in the health domain (Lehto \& Oinas-Kukkonen, 2011) was observed in the selected literature in the present review as well, namely the low level of description regarding the technology and persuasive design involved. Oinas-Kukkonen (2013) has also noted the tendency of behaviour change and persuasive systems research to be lacking in descriptions of the persuasive systems themselves: how they work, what the content is, how they are structured.

Table 2. Persuasive Systems Design Features Identified in the Literature, Categorized by Searched Background Theories (Self-Schema Theory and Transformative Learning Theory).

\begin{tabular}{lcc}
\hline Theory /Persuasive systems features & Self-schema theory & Transformative learning theory \\
\hline Primary task support & Tailoring (through schema matching): Cacioppo & N/A \\
& et al. (1982); Wheeler et al. (2005); Pease, & \\
& Brannon, and Pilling (2006); Pilling and Brannon & \\
& (2007); Brannon and McCabe (2002); York et al. &
\end{tabular}
(2012a); York et al. (2012b)

Personalization: Pilling and Brannon (2007); Dijkstra (2008)

\begin{tabular}{lcc} 
& $\begin{array}{c}\text { Self-monitoring: Pilling and Brannon (2007); } \\
\text { Dijkstra (2008) }\end{array}$ & N/A \\
\hline Computer-human dialogue support & N/A & N/A \\
\hline System credibility & N/A & N/A \\
\hline Social support & Social comparison: Pilling and Brannon (2007) & \\
\hline
\end{tabular}

In the five papers in the present review that involved a technology component, the persuasive features of the system were referred to on rather a superficial level. Naturally, the publications were in the area of psychology, health communications and health marketing, and therefore it will not have been of primary interest to describe the persuasive systems in detail as such. However, the papers do point to certain persuasive design principles that have been discussed by Fogg (2003) and more formally organized as design principles by Oinas-Kukkonen and Harjumaa (2009). Of the five, Wilkerson et al. (2011) merely make a reference to Fogg (2003) as the basis for the persuasive design, but the three papers that discuss schema matching and persuasion are, in PSD terms, presenting a case for tailoring. Tailoring (or customization, as Fogg, 2003, also calls it) is about matching the information provided by a system to the recipient at some identifiable level, such as personality, context of use, or interests (Oinas-Kukkonen \& Harjumaa, 2009). Another article in the reviewed selection, Wheeler et al. (2005), examined self-schema matching and message quality with need for cognition as a self-schema structure and 
found that matching - or tailoring, in PSD terms - message quality to the recipients' schema affects the effectiveness of persuasion.

Dijkstra's (2008) arguments for computer-tailored persuasion included three main concepts: adaptation, personalization and feedback. The concepts are also familiar from Oinas-Kukkonen and Harjumaa (2009), but under slightly different terminology. Adaptation, as described in Dijkstra (2008), is essentially tailoring in PSD terms, and Dijkstra presents a case for psychological processes that are involved when using adaptation as an effective persuasion method. Personalization is a feature that is described in much the same way by both Dijkstra (2008) and Oinas-Kukkonen and Harjumaa (2009), pointing out the benefits of providing content and information that is relevant to the individual user. The principle of personalization is also described by Fogg (2003). Finally, Dijkstra (2008) discusses feedback, which in the PSD model is a design feature called self-monitoring (OinasKukkonen \& Harjumaa, 2009). Though speaking largely from a theoretical point of view, Dijkstra's (2008) approach is one aiming at understanding what features or techniques specifically offer opportunities for persuasion and behaviour change and thus offer guidance to persuasive system design.

\section{Outcome/Change Evaluation of Contributions}

The included articles were evaluated against the O/C Matrix (Table 3) with the intention of determining how clearly any change or outcome was expressed. The analysis consisted of identifying any expectation or result of a behaviour change (change type) and the direction of that change (outcome). What was notable was that since very few of the articles ultimately $(N=5)$ observed a behaviour change intervention or reported an experiment that aimed at documenting change as such, there was little discussion of such change results or targets.

Table 3. Assessment of Change Types and Outcomes in Covered Literature. This Table Visualises Studies in Terms of the O/C Matrix.

\begin{tabular}{|c|c|c|c|}
\hline & C-change & B-change & A-change \\
\hline \multirow[t]{2}{*}{ F-Outcome } & Forming an act of compliance (F/C): & Forming a behaviour (F/B): & Forming an attitude (F/A): \\
\hline & Samenow et al. (2013) & Samenow et al. (2013) & N/A \\
\hline \multirow[t]{2}{*}{ A-Outcome } & Altering an act of compliance $(\mathrm{A} / \mathrm{C})$ : & Altering a behaviour (A/B): & Altering an attitude $(\mathrm{A} / \mathrm{A})$ : \\
\hline & N/A & $\begin{array}{l}\text { Samenow et al. (2013); Wilkerson et } \\
\text { al. (2011) }\end{array}$ & $\begin{array}{l}\text { Pilling and Brannon 2007; Samenow } \\
\text { et al. (2013); York, et al. (2012a); York, } \\
\text { et al. (2012b); Wilkerson et al. (2011) }\end{array}$ \\
\hline \multirow[t]{2}{*}{ R-Outcome } & Reinforcing an act of compliance (R/C): & Reinforcing a behaviour (R/B): & Reinforcing an attitude (R/A): \\
\hline & N/A & Samenow et al. (2013) & Samenow et al. (2013) \\
\hline
\end{tabular}

The majority of the articles focused on examining the effect of a characteristic or a trait (namely, a specified selfschema) on attitudes or behaviour, and as such reported how people with a given self-schema behave or think with regards to a specific behaviour compared to people who do not have that self-schema. Such a comparison is helpful in behaviour change support system design as well, since the said research provides us with a means of predicting behaviour and thus a means of incorporating mechanisms like schema matching in the BCSS designs: knowing what type of message design, voice, or structure is most effective with a targeted self-schema type allows a BCSS designer to use a fine-grained approach for the best possible persuasion results.

Cognitive dissonance, where information conflicts with a self-schema, can also result in a persuasive message being disregarded entirely instead of the ideal outcome of the message leading to a change in the schema (Festinger, 1957, 1962; Markus, 1977). Overall, various studies reported that the persuasive message is received more favourably if it matches the recipient's self-schema (Cacioppo et al., 1982; Pilling \& Brannon, 2007), or that schema matching can increase the impact of persuasive messages (Brannon \& McCabe, 2002; York et al., 2012a, $2012 b)$. Also, the link between a self-schema and actual behaviour in accordance to that self-schema, for example exercising, has been established (Kendzierski, 1988; Kendzierski \& Sheffield, 2000). 
Predominantly, the examined material that indicated an expectation or evidence of behaviour change also did so with regards to 'behaviour' and/or 'attitude'. Pilling and Brannon (2007) as well as York et al. (2012a, 2012b) were interested in the attitude-level response towards messages promoting responsible drinking when the messages were matched to different personality structures. In all three schema-matching experiments self-schema matching resulted in a more positive response to the responsible drinking message. In O/C Matrix terms, then, self-schema matching of persuasive messages can produce an A/A result (alteration of attitude). From the articles it was not possible to deduce if the altering also affected behaviour (this was not followed up), or if there is an opening for formation of attitude (F/A).

The transformative learning studies in the selection offer a more versatile spectrum of change and outcomes. Wilkerson et al. (2011) describe self-reflection leading to a change in perspective (attitude), which in turn appears to lead to change in behaviour: in other words, A/B and A/A. Samenow et al. (2013), through the process-like approach of transformative learning, address all three change types: compliance, behaviour and attitude. A person with a behavioural issue is confronted about the issue and is then (in firm terms) invited to take part in the rehabilitation programme (F/C). Through self-reflection and critical examination of assumptions, a change in the subject's perspective is gained (A/A). By exploring new behaviours, relationships and roles, committing to work on changing problem issues, and using methods such as role play the subject begins to take on more appropriate responses and behaviours (A/B). Finally, the new skills are reinforced by booster sessions in the programme, where further self-reflection is encouraged and the subject takes part in practical activities to reinforce the new behaviour and communication skills (R/A, R/B).

Although papers on transformative learning and behaviour change were far and few between, the case study presented in Samenow et al. (2013) is an interesting indication of how a complete programme of purposeful acts of self-reflection appears to guide a learner through the various change steps as described in the O/C Matrix. In terms of the O/C Matrix it would appear that the self-schema centred findings in the selected literature focus on impact on A-change with A-outcome. Potential for other configurations is not immediately clear from the studies, but other findings in the exercise and healthy eating studies regarding the relationship of self-schemas to behaviour (e.g. Banting, Dimmock, \& Lay, 2009; Kendzierski, Sheffield, \& Morganstein, 2002) point to the effect of the self-schema in maintaining the desired behaviour - an indication of R-outcome, using the terminology of the O/C Matrix.

Earlier in the present review, in theoretical considerations, it was assumed that self-schema structures could predominantly affect the F- and R-outcomes, and that transformative learning was a practical tool for achieving Aoutcome. However, the evidence from the present analysis is inconclusive as regards the restrictions of the full outcome and change potential of using self-schemas as an element in persuasion and behaviour change. The relationship between self-schema and corresponding behaviour, namely exercise behaviour (Sheeran \& Orbell, 2000), continues to suggest that at least R-outcome is a possibility. Markus (1977) described how self-schemas strengthen over time and strong self-schemas can lead to a person becoming more resistive to schemainconsistent information. Such a thought process would suggest a possibility that strong self-schemas can produce a R/A result in terms of the O/C Matrix. The data from the few studies analysed here is not sufficient to rule out these options.

Interestingly, the lack of attention to compliance - which at its simplest means responding to a request by doing as asked - is quite notable. Following instructions, for example a detailed exercise programme or a diet, calls for compliance: the behaviour is produced as requested and because it needs to be done (Oinas-Kukkonen, 2010a). The incremental nature of persuasion (Oinas-Kukkonen \& Harjumaa, 2009) would suggest that learning to repeat a behaviour even when proper intrinsic motivation is lacking can lead to further change types of behaviour and attitude change, where the target behaviour is produced more through intrinsic motivation and self-efficacy. Principles of operant conditioning, stemming from Behaviorism, namely positive and negative reinforcement are some of the key techniques in inducing desired behaviour even when intrinsic motivation is initially missing (Flora, 2004). Equally interesting, apart from the afore-mentioned case of the sustaining effect of self-schema on target behaviour, is that the reviewed papers did not explicitly discuss different types of change outcome, whether a behaviour was simply forming (new), altering (changing shape) or being reinforced. Closest to this continuum was Samenow et al. (2013) in their paper about the transformative learning process as the basis of a behaviour change course for disruptive physicians. 


\section{Discussion}

A systematic literature search was undertaken for academic papers discussing the topics of persuasion and/or behaviour change with the theories of self-schema or transformative learning. An array of more than 500 papers in total was evaluated in stages, finally leaving 20 papers mainly from the fields of psychology, health and marketing. While the search was also aimed at studies that involved a computerized persuasion, the final selection of papers included only a handful of papers that reported the use of an information system in an experiment or intervention $(N=5)$, other than rolling out set questionnaires online. Overall, the change type considered in the papers focused on either impact on behaviour or impact on attitude (or both).

By employing the frameworks of Persuasive Systems Design (PSD) model and Outcome/Change (O/C) Matrix (Oinas-Kukkonen, 2010a, 2010b, 2013; Oinas-Kukkonen \& Harjumaa, 2009) it was possible to review defined elements of persuasion and persuasive technology use between independent studies. Such analysis revealed similar components in the studies, but also identified what typical persuasive system elements were not described.

\section{Implications to Design of BCSSs and Research of Computerized Persuasion}

The more widely used theories from social psychology in persuasion research do touch on the concepts of self and self-schema as such (Fogg, 2003; Oinas-Kukkonen \& Harjumaa, 2009), but in order to move on and improve the effectiveness in, say, the issue of intention-behaviour gap it is necessary to cast the nets wider and look in more detail at some of the social theories that contribute to those established persuasion theories. While Theory of Planned Behaviour (Ajzen, 1991) cannot be claimed to be wrong about the role of intention in predicting behaviour at least to some degree it would seem necessary to try and identify factors and mechanisms that can be added to the equation so that the predictive quality of intention or attitude can be improved. Self-schema is one such structure that can, we believe, help. Some of the previous research has shown that self-schemas have a role in lowering the threshold to produce target behaviour (Kendzierski, 1988) and a role in returning to target behaviour after a lapse (Kendzierski, Sheffield, \& Morganstein, 2002). Examples of transformative learning (such as Samenow et al., 2013) have also indicated that self-schemas, the self-constructs that define how we see various situations around us and our position in those situations, can be altered. It would, therefore, seem both necessary and feasible for BCSS design to discover ways of incorporating attitude-changing processes in overall behaviour change.

Regardless of the relatively low number of identified records in the present review, the findings do consistently point at evidence that a person's concept of self is a relevant construct in behaviour change. Some of the research showed not only that schema-consistent information can be received more favourably (Pilling \& Brannon, 2007; Cacioppo et al., 1982), but also that we can become resistant to schema-inconsistent information (Markus, 1977). It is therefore necessary to recognize that any discourse on the application potential of self-schema based approaches to behaviour change and behavioural design must include the possibility of affecting such self-images - as in transformative learning.

Information systems that are harnessed to the task of encouraging behaviour change are precisely the tools for providing behaviour change support that can be tailored to an end-user's specific targets and even schema types (Dijkstra, 2008). At the same time, these behaviour change support systems are in an excellent position to provide people in need of behaviour change with a means of going through an incremental, step-by-step programme of transformation of perspective - of possibly helping to adjust necessary self-schemas with the intention of making a target behaviour more fluent. In many cases, it would appear important to learn to identify self-schemas and to apply a process to change those schemas that are hindering behaviour change. The O/C Matrix (Oinas-Kukkonen, 2013) is intended as a planning tool to design BCSS content to focus on those exact points of progress that require attention (Langrial, Stibe, \& Oinas-Kukkonen, 2013; Oinas-Kukkonen, 2010b, 2013), and it can be used to make decisions regarding the system design choices, as presented in the PSD model. Assessing the internal attitude structures, self-schemas, of individuals using a BCSS, and applying practical steps as in the transformative learning process can add a layer of detail to the O/C Matrix analysis that will make a difference in the effectiveness of a BCSS. 
The present review and its findings should assist practitioners in identifying opportunities for more sophisticated tailoring of their systems that aim at end-user behaviour change. For researchers the implications of the review findings are towards further identification of operationalizing stage models such as transformative learning in information systems, and in learning how domain specific self-schemas can be identified in system users.

\section{Limitations and Strengths of the Review}

The present review is based on literature searches addressing specific concepts and keywords. The review discovered a relatively small amount of existing research on the defined topics of self-schemas and transformative learning in the context of persuasive technology, despite searching large databases that list information systems research. From this review it is not possible to draw a clear idea of what any used persuasive systems were actually like, or what direct design implications could be drawn from the way persuasive features and their presentations were implemented.

What the review does not address is the existing literature on persuasion and behaviour change that is based on such acknowledged theories as theory of planned behaviour (Ajzen, 1991), Social Learning Theory (Bandura, 1997) or elaboration likelihood model (Petty \& Cacioppo, 1986). This is not to discount these theories in any way; it is merely necessary to state that discussing the theoretical frameworks in the present paper in the context of these core theories is matter for a future undertaking. Another future undertaking that would bring more practical prominence to the discussion of self-schemas is to analyse the theory against actual BCSSs. Further avenues of future work would include exploring the stage-model approach of transformative learning in persuasive technology and BCSS context, and to examine the conclusions in the present paper as regards continuance of technology use.

\section{Conclusion}

The present review examined the use of self-schema Theory and theory of transformative learning in persuasion and behaviour change literature. Despite the limited array of identified studies that incorporated either of the two stated theories alongside purposeful persuasion and behaviour change objective, and particularly despite the lack of identified studies that dealt with these themes in the area of information systems, the review was not without useful results. For one, a body of psychology and health related literature was identified that examined the relationships between self-schemas and behaviour. Detailed understanding of such relationships is of use when designing or analysing BCSSs with the help of the PSD model, and when designing or analysing the targeted change types and outcomes with the O/C Matrix.

Those identified studies which observed changes in behaviour and aimed to explain the extent to which the change was a result of self-schemas help us understand a little better the multifaceted nature of persuasion: individual traits in our psychology can have a profound effect on how a message is perceived, and the value of some PSD principles such as tailoring are highlighted. Computer-mediated or computer-human persuasion is in an ideal position to offer tailored - perhaps even bespoke - BCSSs that respond to end-users' individual characteristics and information processing preferences, but which can effectively be rolled out for the mass market.

\section{Notes}

1. Barclay-Goddard et al. (2012, p. 214) refer to response shift as "change in internal standards, values, or a definition of a construct (e.g. health-related quality of life) over time, commonly seen in individuals with chronic illness." Emergence of a chronic illness can trigger the complex self-reflection process that is transformative learning (Barclay-Goddard et al., 2012). 


\section{References}

\section{* denotes a reference among the reviewed studies}

Abraham, C., \& Michie, S. (2008). A taxonomy of behavior change techniques used in interventions. Health Psychology, 27, 379-387. https://doi.org/10.1037/0278-6133.27.3.379

Ajzen, I. (1985). From intentions to actions: A theory of planned behavior. In J. Kuhl \& J. Beckmann (Eds.), Action control: From cognition to behavior (pp. 11-35). Berlin, Germany: Springer-Verlag.

Ajzen, I. (1991). The theory of planned behavior. Organizational Behavior and Human Decision Processes, 50, 179211. https://doi.org/10.1016/0749-5978(91)90020-T

Bandura, A. (1977). Social learning theory. Englewood Cliffs, NJ: Prentice Hall.

Bandura, A. (1997). Self-efficacy: The exercise of control. New York, NY: W.H. Freeman.

Banting, L. K., Dimmock, J. A., \& Lay, B. S. (2009). The role of implicit and explicit components of exerciser selfschema in the prediction of exercise behavior. Psychology of Sport and Exercise, 10, 80-86.

https://doi.org/10.1016/j.psychsport.2008.07.007

Barclay-Goddard, R., King, J., Dubouloz, C.-J., \& Schwartz, C. E. (2012). Building on transformative learning and response shift theory to investigate health-related quality of life changes over time in individuals with chronic health conditions and disability. Archives of Physical Medicine and Rehabilitation, 93, 214-220.

https://doi.org/10.1016/j.apmr.2011.09.010

Brannon, L. A., \& McCabe, A. E. (2002). Schema-derived persuasion and perception of AIDS risk. Health Marketing Quarterly, 20(2), 31-48. https://doi.org/10.1300/J026v20n02_03

Cacioppo, J. T., Petty, R. E., \& Sidera, J. A. (1982). The effects of a salient self-schema on the evaluation of proattitudinal editorials: Top-down versus bottom-up message processing. Journal of Experimental Social Psychology, 18, 324-338. https://doi.org/10.1016/0022-1031(82)90057-9

Chatterjee S., \& Price A. (2009). Healthy living with persuasive technologies: Framework, issues, and challenges. Journal of the American Medical Informatics Association, 16, 171-178. https://doi.org/10.1197/jamia.M2859

Cialdini, R. B., Petty, R. E., \& Cacioppo, J. T. (1981) Attitude and attitude change. Annual Review of Psychology, 32, 357-404. https://doi.org/10.1146/annurev.ps.32.020181.002041

Consolvo S., McDonald D. W., \& Landay J. A. (2009). Theory-driven design strategies for technologies that support behavior change in everyday life. In CHI '09 Proceedings of the SIGCHI Conference on Human Factors in Computing Systems (pp. 405-414). New York, NY: ACM. https://doi.org/10.1145/1518701.1518766

Cranton, P. (1994). Understanding and promoting transformative learning: A guide for educators of adults. San Francisco, CA: Jossey-Bass.

Cranton, P. (1996). Professional development as transformative learning: New perspectives for teachers of adults. San Francisco, CA: Jossey-Bass.

*Dijkstra, A. (2008). The psychology of tailoring-ingredients in computer-tailored persuasion. Social and Personality Psychology Compass, 2, 765-784. https://doi.org/10.1111/j.1751-9004.2008.00081.x

Festinger, L. (1957). A theory of cognitive dissonance. Stanford, CA: Stanford University Press. 
Festinger, L. (1962). Cognitive dissonance. Scientific American, 207(4), 93-106.

https://doi.org/10.1038/scientificamerican1062-93

Flora, S. R. (2004). The power of reinforcement. Albany, NY: State University of New York Press.

Fogg, B. J. (2003). Persuasive technology: Using computers to change what we think and do. San Francisco, CA: Morgan Kaufmann Publishers.

Fogg, B. J. (2009). A behavior model for persuasive design. In Persuasive '09 Proceedings of the $4^{\text {th }}$ International Conference on Persuasive Technology (Article No. 40). New York, NY: ACM.

https://doi.org/10.1145/1541948.1541999

Kaptein, M., \& Eckles, D. (2012). Heterogeneity in the effects of online persuasion. Journal of Interactive Marketing, 26, 176-188. https://doi.org/10.1016/j.intmar.2012.02.002

Kaptein, M., Markopoulos, P., de Ruyter, B., \& Aarts, E. (2015). Personalizing persuasive technologies: Explicit and implicit personalization using persuasion profiles. International Journal of Human-Computer Studies, 77, 38-51.

https://doi.org/10.1016/j.ijhcs.2015.01.004

Kendzierski, D. (1988). Self-schemata and exercise. Basic and Applied Social Psychology, 9, 45-59.

https://doi.org/10.1207/s15324834basp0901_4

Kendzierski, D., \& Sheffield, A. (2000). Self-schema and attributions for an exercise lapse. Basic and Applied Social Psychology, 22, 1-8. https://doi.org/10.1207/S15324834BASP2201_1

Kendzierski, D., Sheffield, A., \& Morganstein, M. S. (2002). The role of self-schema in attributions for own versus other's exercise lapse. Basic and Applied Social Psychology, 24, 251-260.

https://doi.org/10.1207/S15324834BASP2404_1

Kitchenham, B. (2004). Procedures for performing systematic reviews (Joint Technical Report). Department of Computer Science, Keele University (TER/SE-0401) and National ICT Australia Ltd. (04001T.1). Retrieved from http://www.inf.ufsc.br/ aldo.vw/kitchenham.pdf

Kuonanoja, L., Langrial, S., Lappalainen, R., Lappalainen, P., \& Oinas-Kukkonen, H. (2015). Treating depression through a behavior change support system without face-to-face therapy. AlS Transactions on Human-Computer Interaction, 7, 192-210. Retrieved from https://aisel.aisnet.org/thci/vol7/iss3/6

Langrial, S., Stibe, A., \& Oinas-Kukkonen, H. (2013). Practical examples of mobile and social apps using the Outcome / Change Design Matrix. In Adjunct Proceedings of the 8th International Conference on Persuasive Technology, PERSUASIVE 2013, Sydney, Australia, April 3-5, 2013. Retrieved from http://ceur-ws.org/Vol973/bcss1.pdf

Lehto, T., \& Oinas-Kukkonen, H. (2011). Persuasive features in web-based alcohol and smoking interventions: A systematic review of the literature. Journal of Medical Internet Research, 13(3), e46.

https://doi.org/10.2196/jmir.1559

Lehto, T., \& Oinas-Kukkonen, H. (2015). Explaining and predicting perceived effectiveness and use continuance intention of a behavior change support system for weight loss. Behavior \& Information Technology, 34, 176-189. https://doi.org/10.1080/0144929X.2013.866162

Locke E. A., \& Latham G. P. (2002). Building a practically useful theory of goal setting and task motivation. A 35year odyssey. American Psychologist, 57, 705-717. https://doi.org/10.1037/0003-066X.57.9.705

Markus, H. (1977). Self-schemata and processing information about the self. Journal of Personality and Social Psychology, 35, 63-78. https://doi.org/10.1037/0022-3514.35.2.63 
Markus, H., \& Wurf, E. (1987). The dynamic self-concept: A social psychological perspective. Annual Review of Psychology, 38, 299-337. https://doi.org/10.1146/annurev.ps.38.020187.001503

Mezirow, J. (1981). A critical theory of adult learning and education. Adult Education, 32, 3-24. https://doi.org/10.1177/074171368103200101

Mezirow, J. (1991). Transformative dimensions of adult learning. San Francisco, CA: Jossey-Bass.

Mezirow, J. (1995). Transformative theory of adult learning. In M. Welton (Ed.), In defense of the lifeworld: Critical perspectives on adult learning (pp. 39-70). Albany, NY: State University of New York Press.

Mezirow, J. (1996). Contemporary paradigms of learning. Adult Education Quarterly, 46, 158-172.

https://doi.org/10.1177/074171369604600303

Mezirow, J. (1997). Transformative learning: Theory to practice. New Directions for Adult and Continuing Education, 1997(74), 5-12. https://doi.org/10.1002/ace.7401

Mezirow, J. (2009). Transformative learning theory. In J. Mezirow \& E. W. Taylor (Eds.), Transformative learning in practice: Insights from community, workplace and higher education (pp. 18-32). San Francisco, CA: Jossey-Bass.

Oinas-Kukkonen, H. (2010a). Behavior change support systems: A research model and agenda. In Proceedings of Persuasive Technology: $5^{\text {th }}$ International Conference, PERSUASIVE 2010, Copenhagen, Denmark, June 2010 (pp. 4-14).

Berlin, Germany: Springer-Verlag. https://doi.org/10.1007/978-3-642-13226-1_3

Oinas-Kukkonen, H. (2010b). Prerequisites for successful measuring of ambient persuasive technology. In Proceedings of Measuring Behaviour 2010: $7^{\text {th }}$ International Conference on Methods and Techniques in Behavioral Research (Eindhoven, The Netherlands, August 24-27, 2010) (pp. 491-494). Wageningen, The Netherlands: Noldus Information Technology BV.

Oinas-Kukkonen, H. (2013). A foundation for the study of behavior change support systems. Personal and Ubiquitous Computing, 17, 1223-1235. https://doi.org/10.1007/s00779-012-0591-5

Oinas-Kukkonen, H., \& Harjumaa, M. (2009). Persuasive systems design: Key issues, process model, and system features. Communications of the Association for Information Systems, 24, article 28, 485-500.

https://doi.org/10.17705/1CAIS.02428

Pease, M. E., Brannon, L. A, \& Pilling, V. K. (2006). Increasing selective exposure to health messages by targeting person versus behavior schemas. Health Communication, 19, 231-240.

https://doi.org/10.1207/s15327027hc1903_5

Petty, R. E., \& Cacioppo, J. T. (1986). The elaboration likelihood model of persuasion. Advances in Experimental Social Psychology, 19, 123-205. https://doi.org/10.1016/S0065-2601(08)60214-2

*Pilling, V. K., \& Brannon, L. A. (2007). Assessing college students' attitudes toward responsible drinking messages to identify promising binge drinking intervention strategies. Health Communication, 22, 265-276. https://doi.org/10.1080/10410230701708121

Ploderer, B., Reitberger, W., Oinas-Kukkonen, H., \& van Gemert-Pijnen, J. (2014). Social interaction and reflection for behavior change. Personal and Ubiquitous Computing, 18, 1667-1676. https://doi.org/10.1007/s00779-0140779-y

Prochaska, J. O., \& DiClemente, C. C. (1983). Stages and processes of self-change of smoking: Toward an integrative model of change. Journal of Consulting and Clinical Psychology, 51, 390-395.

https://doi.org/10.1037/0022-006X.51.3.390 
Samenow, C. P., Worley, L. L. M., Neufeld, R., Fishel, T., \& Swiggart, W. H. (2013). Transformative learning in a professional development course aimed at addressing disruptive physician behavior: A composite case study. Academic Medicine, 88, 117-123. https://doi.org/10.1097/ACM.0b013e31827b4cc9

Sheeran, P., \& Orbell, S. (2000). Self-schemas and the theory of planned behaviour. European Journal of Social Psychology, 30, 533-550. https://doi.org/10.1002/1099-0992(200007/08)30:4<533::AID-EJSP6>3.0.CO;2-F

Venkatesh, V., \& Bala, H. (2008). Technology acceptance model 3 and a research agenda on interventions. Decision Sciences, 39, 273-315. https://doi.org/10.1111/j.1540-5915.2008.00192.x

Venkatesh, V., Morris, M. G., Davis, G. B., \& Davis, F. D. (2003). User acceptance of information technology: Toward a unified view. MIS Quarterly, 27, 425-478. https://doi.org/10.2307/30036540

Webster, J., \& Watson, R. T. (2002). Analyzing the past to prepare for the future: Writing a literature review. MIS Quarterly, 26, xiii-xxiii. Retrieved from http://www.jstor.org/stable/4132319

Wheeler, S. C., Petty, R. E., \& Bizer, G. Y. (2005). Self-schema matching and attitude change: Situational and dispositional determinants of message elaboration. Journal of Consumer Research, 31, 787-797.

https://doi.org/10.1086/426613

*Wilkerson, J. M., Danilenko, G. P., Smolenski, D. J., Myer, B. B., \& Simon Rosser, B. R. (2011). The role of critical self-reflection of assumptions in an online HIV intervention for men who have sex with men. AIDS Education and Prevention, 23, 13-24. https://doi.org/10.1521/aeap.2011.23.1.13

*York, V. K., Brannon, L. A, \& Miller, M. M. (2012a). Increasing the effectiveness of messages promoting responsible undergraduate drinking: Tailoring to personality and matching to context. Health Communication, 27, 302-309. https://doi.org/10.1080/10410236.2011.585450

*York, V. K., Brannon, L. A., \& Miller, M. M. (2012b). Marketing responsible drinking behavior: Comparing the effectiveness of responsible drinking messages tailored to three possible "personality" conceptualizations. Health Marketing Quarterly, 29, 49-65. https://doi.org/10.1080/07359683.2012.652578 


\section{Correspondence to:}

Piiastiina Tikka

University of Oulu

P.O. Box 3000

$\mathrm{FI}-90014$ Oulu

Finland

Email: piiastiina.tikka(at)oulu.fi

Editorial record: First submission received on January 24, 2018. Revisions received on February 19, 2019, and June 27, 2019. Accepted for publication on June 27, 2019.

Editor in charge: Kristian Daneback

\section{About Authors}

Piiastiina Tikka, PhD, is a Post-doctoral researcher in information systems with her PhD in applied psychology from University of Northumbria, UK. Her background includes service in industry as a user experience and usability researcher for mobile devices. Her research in information systems focuses mainly on persuasive systems and behaviour change.

Harri Oinas-Kukkonen, Ph.D., is Professor of information systems and Dean of Graduate School in the University of Oulu, Finland. His research has been published in a wide variety of scientific information systems, computer science, human-computer interaction, and health and medical informatics journals. He is a co-author of the book "Humanizing the Web: Change and Social Innovation" (Palgrave Macmillan, 2013). He has been listed among 100 most influential ICT experts in Finland and a key person to whom companies should talk to when developing their strategies for ICT services. His current main research interests include persuasive systems design, behavior change, and humanized technologies. 